Brazilian Journal

of Chemical

\title{
DETERMINATION OF THE LIQUID POOL SURFACTANT AND PROTEIN CONCENTRATION FOR SEMI-BATCH FOAM FRACTIONATION COLUMNS
}

\author{
P. T. V. Rosa ${ }^{1}$, C. C. Santana ${ }^{2}$, and R. G. Carbonell ${ }^{3}$ \\ ${ }^{1}$ Department of Food Engineering, FEA, UNICAMP, \\ Zip Code: 13083-000, Campinas - SP, Brazil. \\ ${ }^{2}$ Department of Biotechnological Processes, FEQ, UNICAMP, \\ Zip Code: 13083-000, Campinas - Brazil. \\ E-mail: santana@feq.unicamp.br \\ ${ }^{3}$ Department of Chemical Engineering, North Carolina State University, \\ 27695-7905, Raleigh - NC USA.
}

(Received: June 14, 2005 ; Accepted: April 14, 2006)

\begin{abstract}
A model is derived for the change with time of the concentration of a surface-active component in the liquid pool of a semi-batch foam fractionation process. The transport of surface-active material to the gasliquid interface was assumed to be limited by the mass transfer rates, and the concentration of the adsorbed material at the interface was assumed to be in equilibrium with the concentration of liquid adjacent to the bubble gas surface. This model was compared to experimental data obtained for semi-batch foam fractionation of aqueous solutions of bovine serum albumin and cetyltrimetylammonium bromide.

Keywords: Foam fractionation; Proteins; Surfactant; Bubble column.
\end{abstract}

\section{INTRODUCTION}

Foam fractionation processes are based on the adsorption of a surface-active material at the gasliquid interface originating in the introduction of a gas phase at the bottom of the liquid that contains the surfactant. The swarm of bubbles ascends in the liquid pool and produces a foam column on the top of the liquid. The foam that leaves the column, after transformed in liquid, will yield a solution with a higher surfactant concentration than the liquid pool due to the drainage of some of the liquid in the foam and the enrichment of solute at the gas-liquid interface.

Since drainage is faster in a more unstable foam column, process efficiency increases with a decrease in surfactant concentration, provided that there is enough surfactant in the liquid to form foam. This factor enables use of the process to separate very dilute solutions of surface-active species where other processes are, in general, economically impractical (Brown et al., 1990). Proteins are surface-active materials that are found downstream of many processes in the dilute concentration regime therefore, foam fractionation techniques can be used either to recover the material or to reduce the amount of nitrogen in the wastewater before release. Some examples of this are the concentration of bovine serum albumin (Ahmad, 1975; Lalchev and Exerowa, 1981; Gehle and Schürgerl, 1984). For instance, lactoferrin is a protein found in human and bovine milk, tears, blood, and other secretory fluids that has been used to prevent infection with potential microbial pathogens by its ability to bind with iron

\footnotetext{
*To whom correspondence should be addressed
} 
$\left(\mathrm{Fe}^{3+}\right)$. Currently, bovine lactoferrin can be purified from milk using ion exchange resin, which is a costly procedure making lactoferrin expensive. The work of Noel et al. (2002) investigated a low-cost foam fractionation process as the first step in separating lactoferrin from milk.

A recent review done by Santana et al. (2003) of downstream processing of proteins using foam fractionation includes a mathematical modeling for the description of the foam column and the separation of binary protein mixtures.

In a semi-batch foam fractionation, the solution is injected into the column at the beginning of the process and the foam is produced continuously. This removal of surface-active material by the foam results in a decrease in the liquid pool surfactant concentration with time. In general, the literature related to foam fractionation is completely experimental or presents models for the foam column. The models for the foam column assume the concentration in the liquid pool to be constant with time, even in a semi-batch processes.

This paper describes a model to predict the depletion with time of the surfactant concentration in the liquid pool. The surface concentration of surfactant is assumed to be in equilibrium with the surfactant concentration in a region adjacent to the gas-liquid interface. The surfactant concentration in the region close to the interface of a given bubble varies with the axial position of the bubble in the liquid pool as a result of the convective mass transfer of surface-active material to this region. The bulk concentration is assumed to be as constant with pool height at a given time. Thus, the final surface concentration of the bubbles is shown to be a function of the adsorption isotherm for the surface-active material, the rate of mass transfer to the interface, and the operational parameters of the process. The variation in bulk concentration with time was determined with a mass balance in the liquid pool. In order to evaluate the accuracy of the model, the theoretical results were compared to experimental measurements of the semibatch foam fractionation of bovine serum albumin and cetyltrimethylammonium bromide.

\section{LIQUID POOL DEPLETION}

The model for changes in liquid pool surfactant concentration with time was derived from a mass balance of liquid in the pool, a mass balance for the surfactant in the liquid pool and a mass balance for surfactant at the surface of the bubbles. In Figure 1 one can observe in Figure 1 a diagram of the liquid pool and some of the variables used in setting up the mass balance equations.

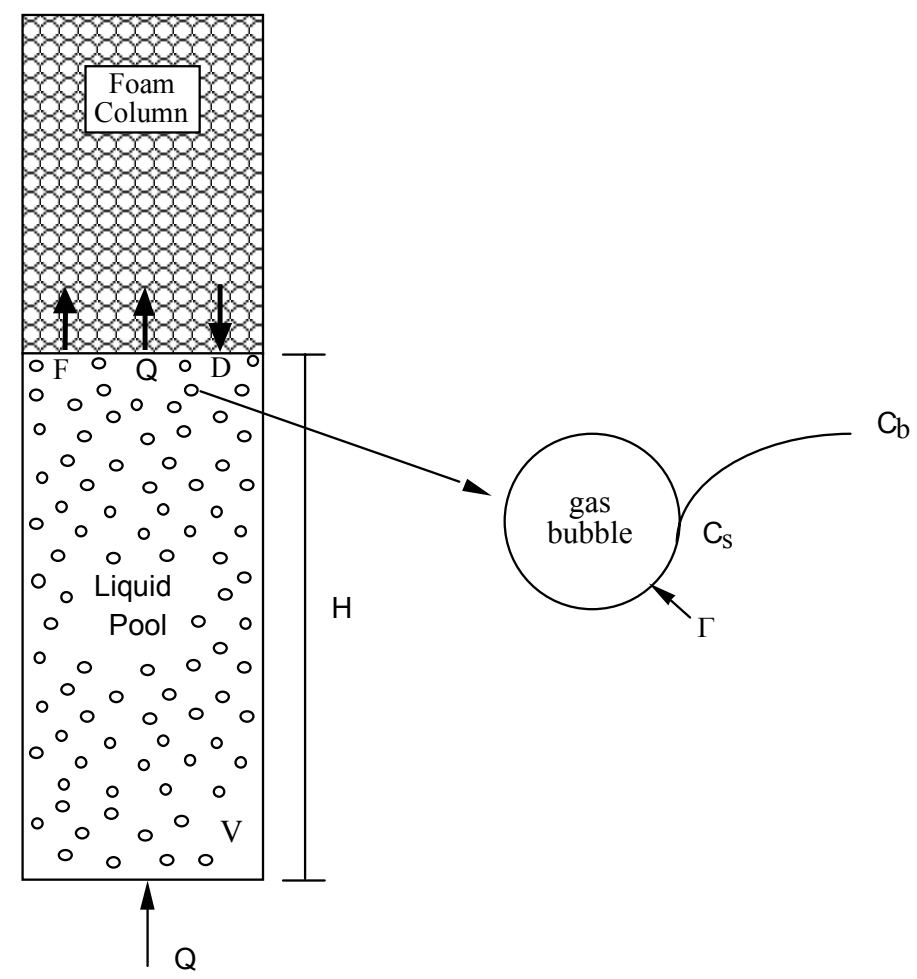

Q - Volumetric Gas Flow Rate

F -Uptake Liquid Flow Rate

D - Drainage Flow Rate

H - Liquid Pool Height

V - Liquid Pool Volume

$\mathrm{Cb}$-Bulk Surfactant Concentration

Cs - Sublayer Surfactant Concentration

$\Gamma$-Surface Concentration

Figure 1: Diagram of the liquid pool and of the surface of a bubble. 


\section{Mass Balance of the Liquid in the Pool}

At the exit to the liquid pool, the liquid is dragged by the gas bubbles as they enter the foam column and a fraction of that liquid returns to the liquid pool as a result of foam drainage. The gas used for foam fractionation is assumed to be saturated with water in order to prevent evaporation of the liquid, therefore it is assumed that the gas composition remains constant in the liquid pool. Thus, the mass balance equation for the liquid in the pool is given by

$$
\mathrm{D}=\mathrm{F}+\frac{\mathrm{d}}{\mathrm{dt}}\left[\left(1-\varepsilon_{\mathrm{g}}\right) \mathrm{V}\right]
$$

In equation (1), $\mathrm{D}$ is the volumetric drainage flow rate, $\mathrm{F}$ is the volumetric uptake flow rate, $\mathrm{V}$ is the volume of the liquid pool, and $\varepsilon_{\mathrm{g}}$ is the gas holdup in the liquid pool.

\section{Surfactant Mass Balance in the Liquid Pool}

The surfactant is carried out of the liquid pool by the foam, both adsorbed at the gas-liquid interface and in the interstitial region containing entrained liquid. Some of the surfactant removed from the liquid column by the foam returns as a result of foam drainage. As the liquid volume in the interstitial region is much larger than that at the bubble surface it was assumed that the up flow is practically composed of the interstitial liquid in the foam, and the mass balance for surface active species can be written as

$$
\begin{aligned}
& \mathrm{DC}_{\mathrm{d}}=\mathrm{FC}_{\mathrm{f}}+\frac{\mathrm{Q}}{\mathrm{V}_{\mathrm{b}}} \mathrm{A}_{\mathrm{b}} \Gamma_{\text {exit }}+ \\
& +\frac{\mathrm{d}}{\mathrm{dt}}\left[\frac{\mathrm{V} \varepsilon_{\mathrm{g}}}{\mathrm{V}_{\mathrm{b}}} \mathrm{A}_{\mathrm{b}} \Gamma_{\mathrm{m}}+\left(1-\varepsilon_{\mathrm{g}}\right) \mathrm{VC}_{\mathrm{b}}\right]
\end{aligned}
$$

In equation (2), $C_{d}$ is the surfactant concentration in the draining liquid, $\mathrm{C}_{\mathrm{f}}$ is the concentration of surfactant in the interstitial liquid in the foam, Q is the volumetric gas flow rate, $\mathrm{V}_{\mathrm{b}}$ is the volume of one bubble, $A_{b}$ is the area of one bubble, $\Gamma_{\text {exit }}$ is the surfactant surface concentration at the exit of the liquid pool, $\Gamma_{\mathrm{m}}$ is the average surfactant interfacial concentration in the liquid pool, and $\mathrm{C}_{\mathrm{b}}$ is the bulk surfactant concentration in the liquid pool.

The first term of the time derivative can be neglected as the amount of surfactant in the liquid pool is much larger than the quantity adsorbed at the surface of the bubbles.

The interstitial surfactant concentration in the foam, $\mathrm{C}_{\mathrm{f}}$, is the same as the surfactant concentration in the liquid pool, $\mathrm{Cb}_{\mathrm{b}}$, since it is formed of the solution being dragged out of the column. If the rate of bubble coalescence is low, the drained surfactant concentration $\left(\mathrm{C}_{\mathrm{d}}\right)$ is also approximately equal to $\mathrm{C}_{\mathrm{b}}$.

The gas holdup in the liquid pool is, in general, below 0.03 thus $\left(1-\varepsilon_{\mathrm{g}}\right)$ was considered to be one and equation (2) can be approximated by

$$
\begin{aligned}
& \left\{\mathrm{D}-\mathrm{F}-\frac{\mathrm{d}}{\mathrm{dt}}\left[\left(1-\varepsilon_{\mathrm{g}}\right) \mathrm{V}\right]\right\} \mathrm{C}_{\mathrm{b}}= \\
& =\frac{\mathrm{Q}}{\mathrm{V}_{\mathrm{b}}} \mathrm{A}_{\mathrm{b}} \Gamma_{\text {exit }}+\left(1-\varepsilon_{\mathrm{g}}\right) \mathrm{V} \frac{\mathrm{dC}_{\mathrm{b}}}{\mathrm{dt}}
\end{aligned}
$$

Substituting equation (1) into (3) and rearranging it, it is possible to show that

$\frac{\mathrm{dC}_{\mathrm{b}}}{\mathrm{dt}}=-\frac{\mathrm{Q}}{\mathrm{V}} \frac{\mathrm{A}_{\mathrm{b}}}{\mathrm{V}_{\mathrm{b}}} \Gamma_{\text {exit }}=-\frac{6 \mathrm{~V}_{\mathrm{g}}}{\mathrm{H} \mathrm{d}_{\mathrm{b}}} \Gamma_{\text {exit }}$

where $\mathrm{V}_{\mathrm{g}}$ is the superficial gas velocity, $\mathrm{H}$ is the liquid pool height, and $d_{b}$ is the mean bubble diameter. In equation (4) it was assumed that the bubbles are spherical and thus the ratio between bubble area and bubble volume is represented by $6 / \mathrm{d}_{\mathrm{b}}$. The superficial gas velocity is defined as the ratio between volumetric gas flow rate and the cross sectional area of the column.

Equation (4) represents the variation in surfactant concentration in the liquid pool with time for a semibatch foam fractionation column. In order to solve this equation it is necessary to know the value of the interfacial concentration of the surface-active material at the exit of the liquid pool. This value can be obtained through a surfactant mass balance around the gas bubbles in the liquid pool.

\section{Mass Balance in the Bubbles in the Liquid Pool}

The model for adsorption of surface-active materials in the bubbles is similar to that proposed by Ward and Tordai (1946). When the bubbles enter the liquid pool, the surfactant found in a thin layer around the bubbles will completely and instantaneously be adsorbed at the interface. This will criate a sub layer in which surfactant 
concentration is different from the bulk, and it can be assumed that the surface concentration and the sub layer concentration are in equilibrium. The sub layer concentration will increase during the ascension of the bubbles in the liquid pool as a result of mass transfer due to the concentration gradient between this region and the bulk region. In Figure 1 one can observe a scheme of the surface of the bubble.

The interfacial mass balance equation obtained for this system can be written as

$$
\begin{aligned}
& \frac{\mathrm{d} \Gamma}{\mathrm{d} \tau}=\frac{\mathrm{k}_{\mathrm{L}} \mathrm{a}\left(\mathrm{C}_{\mathrm{b}}-\mathrm{C}_{\mathrm{s}}\right) \mathrm{V}_{\mathrm{b}}}{\mathrm{A}_{\mathrm{b}} \varepsilon_{\mathrm{g}}}= \\
& =\frac{\mathrm{k}_{\mathrm{L}} \mathrm{a}\left(\mathrm{C}_{\mathrm{b}}-\mathrm{C}_{\mathrm{s}}\right) \mathrm{d}_{\mathrm{b}}}{6 \varepsilon_{\mathrm{g}}}
\end{aligned}
$$

where $\Gamma$ is the surfactant surface concentration, $\tau$ is the rising time of the bubbles, $\mathrm{kL}_{\mathrm{L}}$ is the volumetric mass transfer coefficient, and $\mathrm{C}_{\mathrm{S}}$ is the surfactant concentration of the sub layer.

The variation in surface concentration with time can be converted to variation into pool height

$\frac{\mathrm{d} \Gamma}{\mathrm{d} \tau}=\frac{\mathrm{d} \Gamma}{\mathrm{dz}} \frac{\mathrm{dz}}{\mathrm{d} \tau}=\mathrm{v} \frac{\mathrm{d} \Gamma}{\mathrm{dz}}=\frac{\mathrm{V}_{\mathrm{g}}}{\varepsilon_{\mathrm{g}}} \frac{\mathrm{d} \Gamma}{\mathrm{dz}}$

where $\mathrm{v}$ is the interstitial velocity of the bubbles in the liquid pool.

Substituting equation (6) into (5), and rearranging it, it is possible to show that

$\frac{\mathrm{d} \Gamma}{\mathrm{dz}}=\frac{\mathrm{k}_{\mathrm{L}} \mathrm{a} \quad \mathrm{d}_{\mathrm{b}}\left(\mathrm{C}_{\mathrm{b}}-\mathrm{C}_{\mathrm{s}}\right)}{6 \mathrm{~V}_{\mathrm{g}}}$

If $\mathrm{k}_{\mathrm{L}} \mathrm{a}$ and $\mathrm{d}_{\mathrm{b}}$ do not vary with liquid height, equation (7) can be integrated to produce

$$
\int_{0}^{\Gamma_{\text {exit }}} \frac{\mathrm{d} \Gamma}{\left(\mathrm{C}_{\mathrm{b}}-\mathrm{C}_{\mathrm{s}}\right)}=\int_{0}^{\mathrm{H}} \frac{\mathrm{k}_{\mathrm{L}} \mathrm{a} \mathrm{d}_{\mathrm{b}}}{6 \mathrm{~V}_{\mathrm{g}}} \mathrm{dz}=\frac{\mathrm{k}_{\mathrm{L}} \mathrm{a} \mathrm{d}_{\mathrm{b}} \mathrm{H}}{6 \mathrm{~V}_{\mathrm{g}}}
$$

The value of $\Gamma_{\text {exit }}$ can be determined using equation (8) if the adsorption isotherm data $\Gamma=\Gamma\left(\mathrm{C}_{\mathrm{s}}\right)$ and an adequate correlation for $\mathrm{k}_{\mathrm{L}} \mathrm{a}$ are available. For instance, the work of Graham and Phillips (1979) provides isotherm data for the proteins bovine serum albumin, lysozyme, and $\beta$-casein. The isotherm data for those proteins were modeled by Guzman et al. (1986) and more recently by
Fainerman et al. (2003). There are several correlations for $\mathrm{kLa}_{\mathrm{L}}$ in bubble columns available in the literature (Akita and Yoshida, 1973; Hikita et al., 1981; Kawase et al. 1987; Özturk et al., 1987; Cho and Wakao, 1988; Akita, 1989). Deckwer and Schumpe (1993) established a comparison between several correlations and experimental data and they concluded that the Özturk et al. correlation can better represent the experimental data.

In the solution of equations (4) and (8) the liquid pool was assumed to be in a pseudo steady state, which means that the liquid pool concentration, liquid pool height, and mean bubble diameter remain constant during the rise of a given bubble. This assumption seems reasonable due to the fact that bubble rising time is too short to consider any variation in the system.

In order to verify the model developed, some experiments on semi-batch foam fractionation of bovine serum albumin solutions in phosphate buffer $\mathrm{pH} 7.0$ and ionic strength of $0.1 \mathrm{M}$ in $\mathrm{NaCl}$, using superficial gas velocities of $0.15,0.30$, and 0.45 $\mathrm{cm} / \mathrm{s}$, were carried out as described in the following section. The model was also tested with experimental data on semi-batch foam fractionation of cetyltrimethylammonium bromide obtained from Morgan et al. (1992).

\section{MATERIALS AND METHODS}

The water used in this work was purified by reverse osmosis (ROpure ST - Barnstead) followed by deionization (NANOpure - Barnstead) with a resistivity of $18.3 \mathrm{Mohm} / \mathrm{cm}$. The phosphate buffer (pH 7.0 and ionic strength 0.1) was prepared with monobasic sodium phosphate, dibasic, sodium phosphate, and sodium chloride (ACS grade) obtained from Fisher, and was filtered with a $0.22 \mu \mathrm{m}$ membrane (MSI) prior to use. The protein was bovine serum albumin (BSA - Sigma A-7030, 98\% purity, lot 13H0329) and was used without further purification. The protein concentrations of diluted solutions were determined using a Bio Rad Protein Assay (Bio Rad). The gas used in this work was nitrogen obtained from Union Carbide Co. (UN 1066).

The column was made of glass with an internal diameter $3.45 \mathrm{~cm}$ and a height of $126 \mathrm{~cm}$. The gas distribution system was a Pyrex $30 \mathrm{ml}$ ASTM 10-15 $\mathrm{M}$ filter. Figure 2 shows the experimental apparatus used in this work. This column has six ports where could be taken samples of the protein solution. The volumetric gas flow rate was measured with a rotameter (Cole Parmer). 


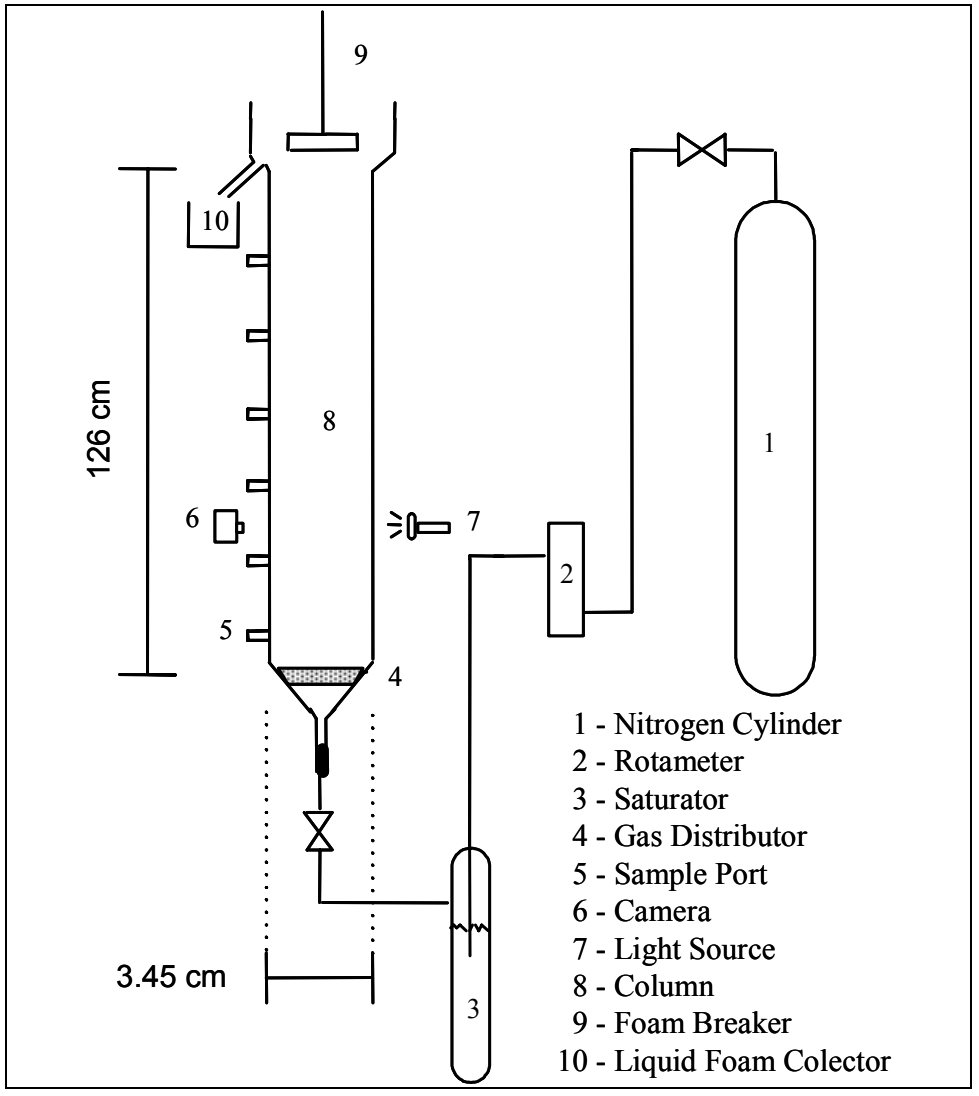

Figure 2: Schematic illustration of the experimental apparatus.

\section{Determination of Protein Concentration}

The protein concentration in the liquid produced after the foam break was measured directly by absorption at $280 \mathrm{~nm}$. This measure is not very sensitive for low concentrations. Thus, the Bradford microassay method (Bradford, 1976) was used to determine the liquid pool protein concentrations below $50 \mathrm{mg} / \mathrm{l}$. These solutions were diluted for final concentration between 5 and $20 \mathrm{mg} / \mathrm{l}$ before reaction. The Bio Rad reagent was filtered with a $0.2 \mu \mathrm{m}$ Acrodisc membrane (Gelman Sciences). All absorption measurements were conducted in a Shimadzu UV-160 spectrophotometer.

\section{Bubble Size Distribution in the Liquid Pool}

Bubble size is a key variable for predicting the ability to separate and concentrate proteins in a foam fractionation process. It is used to characterize not only the bubble-specific interfacial area but also coalescence of the bubbles in the foam phase. In their work, Du et al. (2001) developed a photoelectric method for measuring the bubble size distribution in both bubble and foam columns for concentrating proteins. The method uses a vacuum to remove a stream of gas-liquid dispersion from the bubble or foam column through a capillary tube with a funnelshaped inlet. Because of its simplicity, we decided to use a photographic method to determine the bubble size distribution. Figure 3 shows a scheme of the experimental apparatus used to take pictures of the bubbles in the liquid pool. A Nikon F2 camera coupled with a Nikkor f $35 \mathrm{~mm}$ lens and three closeup lenses was used. The film used was Kodak Ektachrome, 200 ASA (slide). The illumination was provided by two $250 \mathrm{~W}$ lamps located $30 \mathrm{~cm}$ away from the column. There was a $135^{\circ}$ angle between the camera and each light bulb. A light diffuser was used to provide indirect light in the column. The camera was positioned $15 \mathrm{~cm}$ away from the column. With this apparatus it was possible to take pictures of bubbles between 5 and $30 \mathrm{~cm}$ from the distributor plate. There were two scales on the outside surface of the column that were used to determine bubble size. The glass distortion was determined with a $1.15 \mathrm{~mm}$ diameter stainless steel wire, placed inside the column, close to the wall. After development, the film was projected on a white paper and the bubble diameter was measured for several bubbles. 


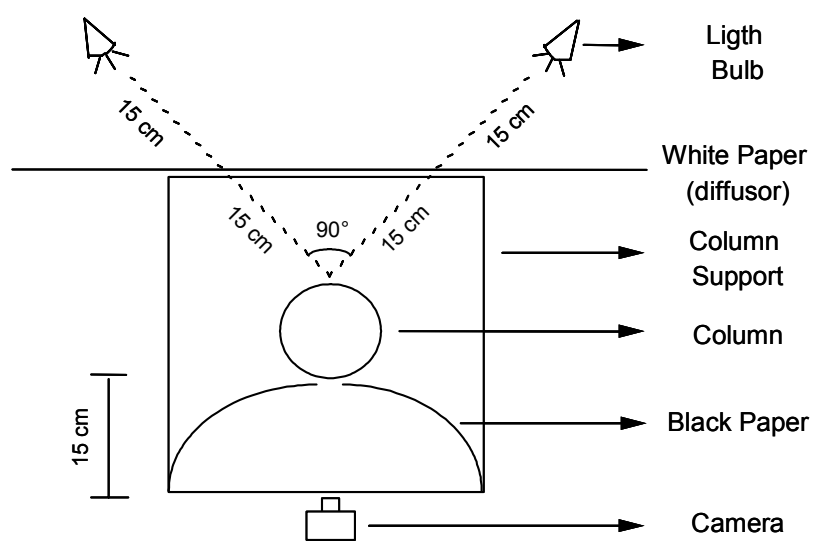

Figure 3: Scheme of the experimental apparatus used to determine bubble size in the liquid pool.

\section{Column Operation}

The experimental run started with the introduction of $600 \mathrm{ml}$ of protein solution into the fractionation column, generating a liquid pool with a height of $64.2 \mathrm{~cm}$. This was followed by the introduction of gas with a specific superficial velocity. Zero time was considered to be when the first bubbles reached the top of the liquid pool. The properties monitored during the experiments were liquid pool height, liquid pool and liquid foam protein concentrations, liquid foam flow rate, and bubble diameters. Liquid pool samples $(2 \mathrm{ml})$ were collected with a syringe at the first port. The first port was located $4.5 \mathrm{~cm}$ from the gas distributor. The foam that left the fractionation column was broken using a two-blade flat impeller centered over the foam column. The column was cleaned after each experiment with an abundant amount of water.

\section{Resolution of the Mass Balance Equations}

The correlation for kLa proposed by Özturk et al. (1987) used to determine the $\Gamma_{\text {exit }}$ value with equation (8), is given by

$$
\begin{aligned}
& \frac{\mathrm{k}_{\mathrm{L}} \mathrm{a} \mathrm{d}_{\mathrm{b}}^{2}}{\mathrm{D}_{\mathrm{i}}}=0.62\left(\frac{\mu_{1}}{\rho_{\mathrm{l}} \mathrm{D}_{\mathrm{i}}}\right)^{0.5}\left(\frac{\mathrm{g} \rho_{\mathrm{l}} \mathrm{d}_{\mathrm{b}}^{2}}{\gamma}\right)^{0.33} \\
& \left(\frac{\mathrm{g} \rho_{1}^{2} \mathrm{~d}_{\mathrm{b}}^{3}}{\mu_{1}^{2}}\right)^{0.29}\left(\frac{\mathrm{V}_{\mathrm{g}}}{\sqrt{\mathrm{gd}}}\right)^{0.68}\left(\frac{\rho_{\mathrm{g}}}{\rho_{\mathrm{l}}}\right)^{0.04}
\end{aligned}
$$

In equation (9) $D_{i}$ is the diffusion coefficient of the surfactant, $\mu$ is the liquid viscosity, $\rho l$ is the liquid density, $g$ is the gravity acceleration, $\gamma$ is the surface tension, and $\rho_{\mathrm{g}}$ is the gas density. In order to fit the experimental data, Özturk et al. (1987) assumed that the bubble diameter was constant and equal to $3 \mathrm{~mm}$.

In order to solve the system of equations, the theoretical area below the curve of $1 /\left(\mathrm{C}_{\mathrm{b}}-\mathrm{C}_{\mathrm{S}}\right)$ is calculated from the right side of equation (8). The values of $\mathrm{C}_{\mathrm{S}}$ as a function of $\Gamma$ are obtained from isotherm data like those provided by Graham and Phillips (1979). The values of $\Gamma_{\text {exit }}$ are determined from the numerical integration, using the trapezoidal rule, on the left side of the same equation. With a given $\Gamma_{\text {exit value, the liquid pool concentration at a }}$ new time is obtained from equation (4), solved by using finite differences. The value of $1 /\left(\mathrm{C}_{b}-\mathrm{C}_{\mathrm{S}}\right)$ for each value of $\Gamma$ is recalculated for each time and the process is repeated until the final time.

\section{RESULTS AND DISCUSSIONS}

\section{Bubble Size in the Liquid Pool}

In order to determine the mean bubble diameter, between 62 and 150 bubble diameters were measured from the slides obtained by the photographic method. The number of bubbles counted was a function of the number of bubbles appearing clearly in the picture. At the beginning of the experiment, the number of bubbles was high but it decreased with time. The bubble diameters measured were separated into classes $0.1 \mathrm{~mm}$ in width and the number of bubbles per class was plotted as a function of the diameter of the mid point of the class. In Figure 4 is shown an example of the distribution of bubble diameters obtained. The distribution was unimodal for all pictures. 
With the distribution of bubble diameters, one can determine a mean bubble diameter that represents the swarm of bubbles. The Sauter mean bubble diameter was used to calculate the mean bubble size and it is defined as

$$
\mathrm{d}_{\mathrm{b}}=\frac{\sum \mathrm{n}_{\mathrm{i}} \mathrm{d}_{\mathrm{b}_{\mathrm{i}}}^{3}}{\sum \mathrm{n}_{\mathrm{i}} \mathrm{d}_{\mathrm{b}_{\mathrm{i}}}^{2}}
$$

In equation (10) $n_{i}$ is the number of bubbles in the class for which the diameter of the mid class is $\mathrm{d}_{\mathrm{bi}}$. The Sauter mean bubble diameter represents the relationship between the volume and area of the bubbles.

The Sauter mean bubble diameter as a function of time and superficial gas velocity can be seen in Figure 5. One can observe in this figure that the value of the bubble diameter is almost constant up to a certain time and after that an increase in the bubble diameter occurs. According to Graham and Phillips (1979), the equilibrium surface tension of BSA solutions in phosphate buffer is constant and has a value of 55 $\mathrm{mN} / \mathrm{m}$ for all the concentration range of our experiments. This constant value of equilibrium surface tension may be responsible for the almost constant value of bubble diameter at the beginning of the experiments. After some time, the protein concentration in the liquid pool is low and the system is no longer in equilibrium. A lack of equilibrium can cause an increase in the surface tension and thus in the bubble diameter. Figure 5 also shows that bubble diameter increases with superficial gas velocity. Increases in superficial gas velocity will increase the number of bubbles on the distributor gas plate and this can produce higher rates of coalescence of bubbles and consequently, an increase in bubble diameter (Ahmed and Dickinson, 1990).

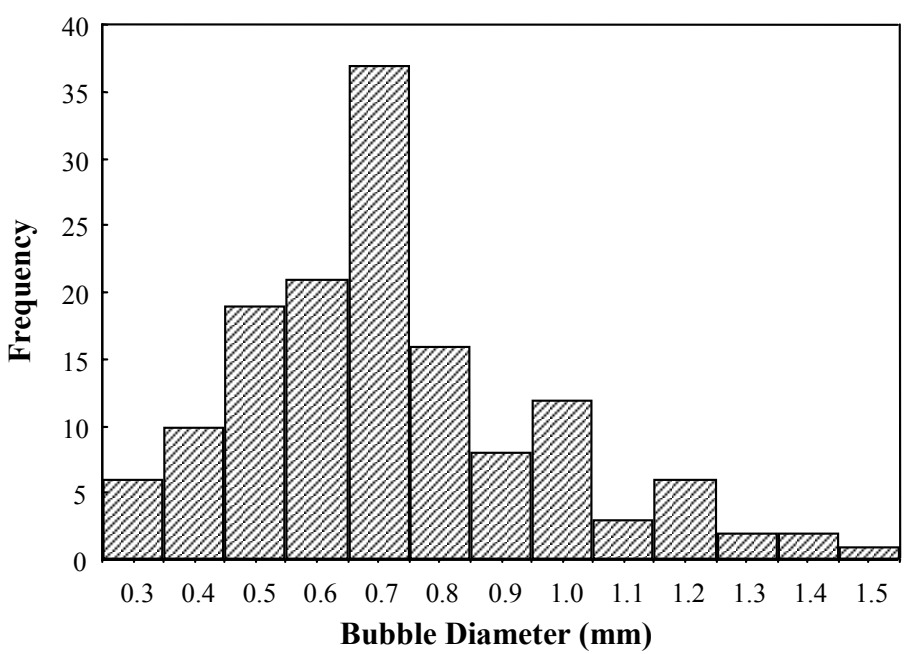

Figure 4: Example of the bubble size distribution in the liquid pool. Initial protein concentration of $100 \mathrm{mg} / \mathrm{l}$, superficial gas velocity of $0.15 \mathrm{~cm} / \mathrm{s}$, and time of $20 \mathrm{~min}$.

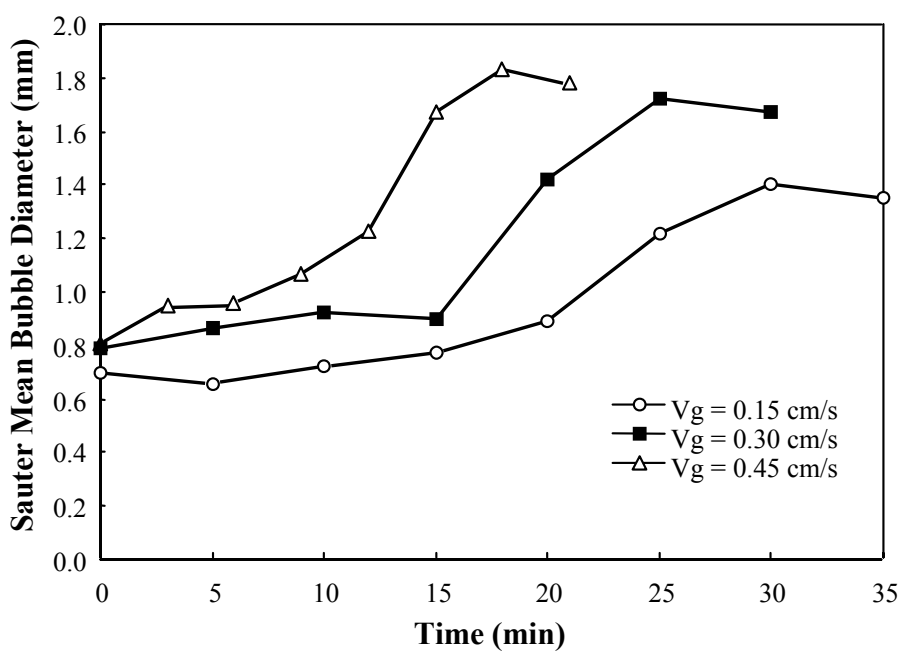

Figure 5: Variation in Sauter mean bubble diameter with time and superficial gas velocity. 


\section{Liquid Pool Height}

The experimental variation in liquid pool height with time and superficial gas velocity is illustrated in Figure 6.

The variation in liquid pool height with time is a function of the amount of liquid that is dragged by the bubbles at the exit of the liquid pool and by the return of the liquid that is drained from the foam column. At the beginning of the experiments the rate of liquid removal from the liquid pool is higher than the rate of liquid drainage from the foam column. Thus, the liquid pool height decreases with time. It is possible to observe in Figure 6 that the rate of decrease in the height of the liquid pool is higher for larger superficial gas velocities. This kind of behavior can be explained by the increase in the rate of formation of a gas-liquid interface with the increase in superficial gas velocity since the amount of liquid that is dragged from the liquid pool is a function of the area of the bubbles. The number of bubbles generated per unit of time is almost constant due to the increase in bubble diameter with the increase in superficial gas velocity. Another factor that causes the higher rate of decrease in height of the liquid pool for higher superficial gas velocities is the lower residence time of the bubbles, which induces a decrease in the rate of drainage of the foam column.

After some time, the concentration of protein in the liquid pool is low and the bubble diameter increases. The increase in bubble diameter results in an increase in the rate of drainage in the foam column (Rand and Kraynik 1983, Manev et al. 1984, and Sarma and Khilar 1988). The rate of drainage of the foam column increases and its value can be higher than the rate of dragging of the liquid from the liquid pool. When this happens, the liquid pool height tends to increase with time. This could be observed at the end of the experiments (Figure 6).

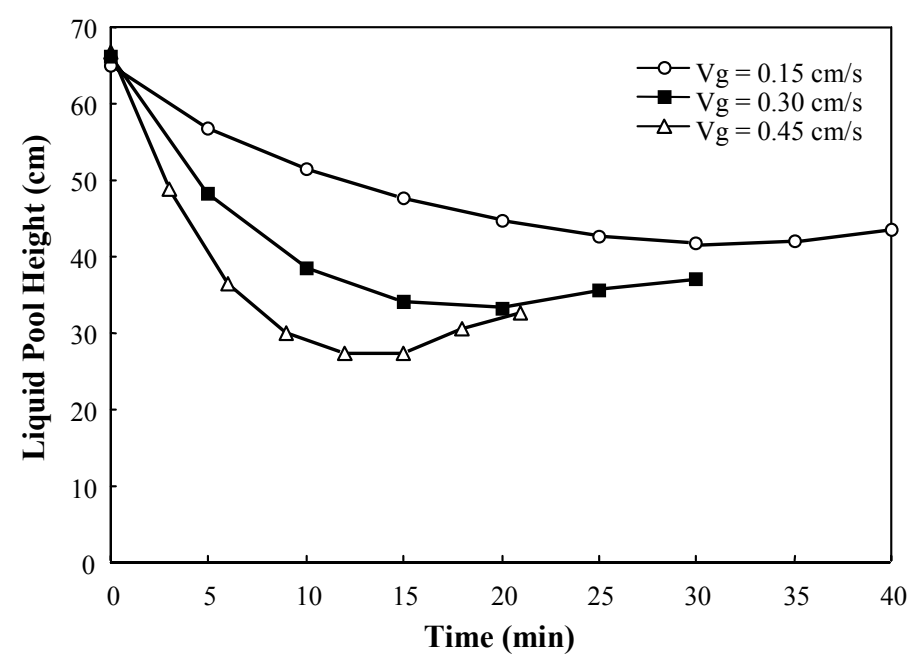

Figure 6: Variation in liquid pool height with time and superficial gas velocity.

\section{Liquid Foam Flow Rate}

The behavior of the rate of production of protein solution that is produced at the top of the fractionation column by the breakage of foam bubbles is shown in Figure 7. When the experiments start there are no bubbles in the foam column and thus there is no production of solution at the top of the fractionation column. During the time that the bubbles start to fill the foam column, the rate of breakage of bubbles is high due to the air-bubble interface, which allows evaporation of some of the liquid in the films that can induce film breakage, and the nonwet wall of the foam column. The breakage of the bubbles increases the drainage of the foam column and a low value can be observed for the flow rate of the first sample of liquid foam obtained from the column. After this period, the foam column is more highly stable and reaches a maximum value of the liquid foam flow rate. Subsequently, the rate of drainage of the foam column increases and the production of the liquid foam decreases with time.

The output of liquid foam at the top of the column increases for higher superficial gas velocities, since the amount of liquid that is dragged by the bubbles is higher under these conditions. The total volume of solution that is removed from the system is equal to the area below the curve for the flow of liquid foam with time and is 180, 245 and $280 \mathrm{ml}$ for superficial gas velocities of $0.15,0.30$ and $0.45 \mathrm{~cm} / \mathrm{s}$, respectively. 


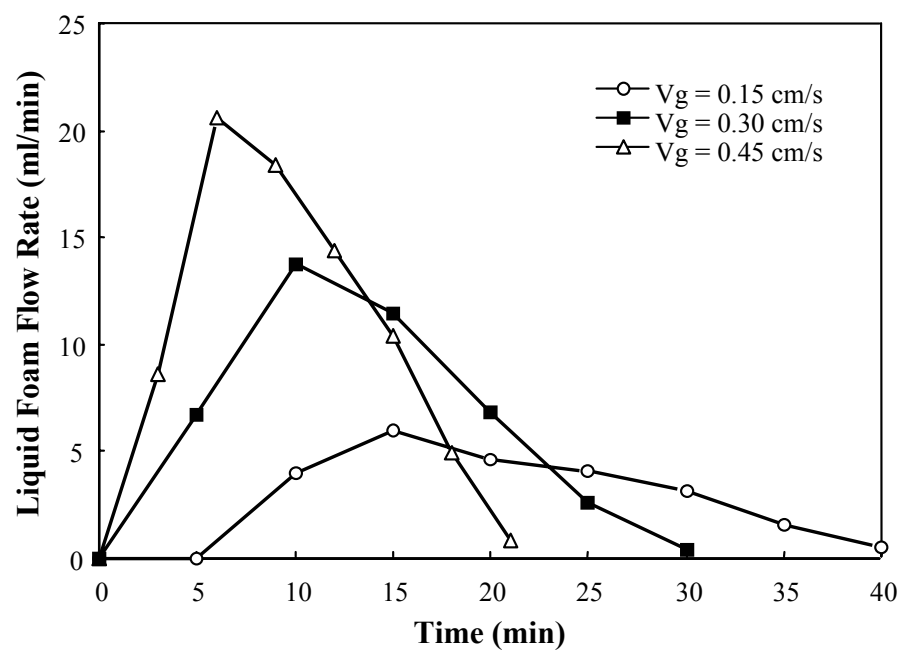

Figure 7: Changes in the liquid foam flow rate with time and superficial gas velocity.

\section{Liquid Foam Protein Concentration}

In Figure 8 is shown the experimental variation in the liquid foam protein concentration with time and superficial gas velocity. Three regions can be observed in this figure. At the first experimental point, the protein concentration in the liquid foam is high due to the high rate of breakage of the bubbles in the foam column. When one bubble breaks, the protein that is adsorbed at the gas-liquid interface is released into the interstitial liquid of the foam. This causes an increase in the protein concentration in the liquid and a possible new adsorption of the released protein on the surface of the bubbles. The concentration of liquid foam is a function of both the amount of protein that is adsorbed at the gas-liquid interface and the amount of protein in the interstitial liquid thus the breakage of bubbles gives a higher protein concentration in the liquid foam. The second region is characterized by an almost constant value for foam concentration with time which is lower than the value at the first point. In this region the foam is relatively stable. The third region occurs at the end of the experiment and there is an increase in foam concentration due to the increase in drainage rate. The increase in drainage rate induces the production of drier foam at the top of the column and therefore the importance of the amount of protein adsorbed at the gas-liquid interface is more marked.

The concentration of liquid foam is higher for lower superficial gas velocities due to the longer residence time of the bubbles in the foam column and to the small amount of liquid that is carried with the bubbles. The difference in the three regions is more noticeable for lower superficial gas velocities.

The liquid foam concentration is between two and five times higher than the initial protein concentration.

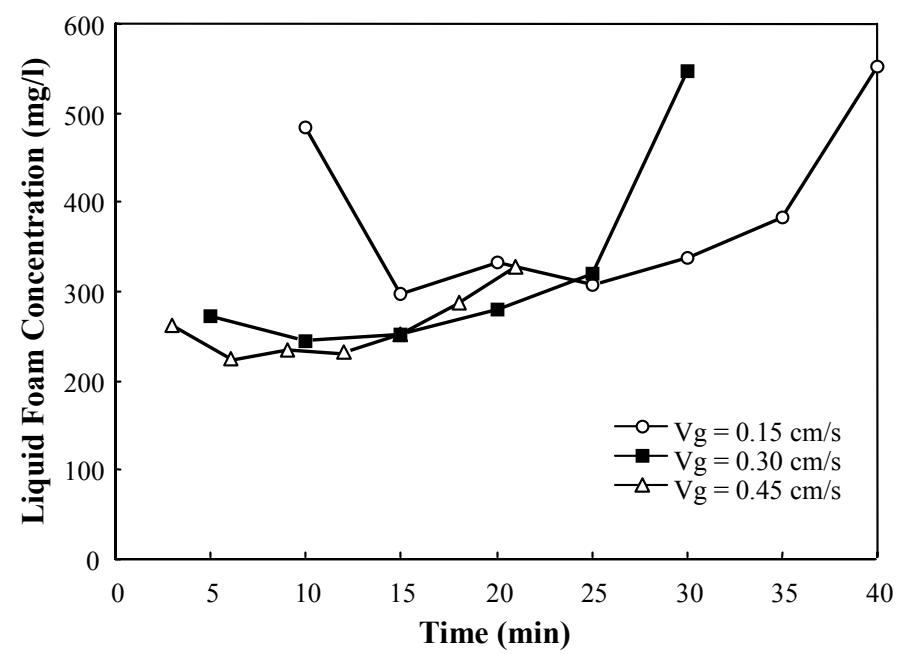

Figure 8: Variation in the liquid foam concentration with time and superficial gas velocity. 


\section{Liquid Pool Protein Concentration}

Figure 9 shows the variation in liquid pool protein concentration with time and superficial gas velocity. The variation in BSA concentration in the liquid pool occurs at a low rate between the first and second experimental points. In this period, the rate of breakage of bubbles is high and the concentration of the interstitial liquid is consequently high. Thus, some protein that leaves the liquid pool adsorbed at the gas-liquid interface will return to this column with the drained liquid of the foam column. This effect is more observable for low superficial gas velocities due to the higher residence time of the bubbles in the foam column and higher rate of bubble breakage. Subsequently, the rate of bubble breakage in the foam column diminishes and an even decrease in the liquid pool concentration can be observed with time.
The rate of decrease in the liquid pool concentration is fasterer for higher superficial gas velocities. This happens due to the increase in the rate of area of the bubble surface formation for higher gas flow rates. The area of the gas-liquid interface is very important for the fractionation process, since the surfactant molecule will be adsorbed in this region. The final concentration of surfactant in the liquid pool was practically independent of the superficial gas velocity, and the final concentration was between 7 and $9 \mathrm{mg} / \mathrm{l}$. These liquid pool concentrations probably represent the lowest protein concentration that can form a foam column. In spite of the faster decrease in liquid pool concentration for higher superficial gas velocities, the final volume of solution that remains in the liquid pool is smaller and the final solution volumes in the liquid pool were 420,350, and $320 \mathrm{ml}$ for superficial gas velocities of $0.15,0.30$, and 0.45 $\mathrm{cm} / \mathrm{s}$, respectively.

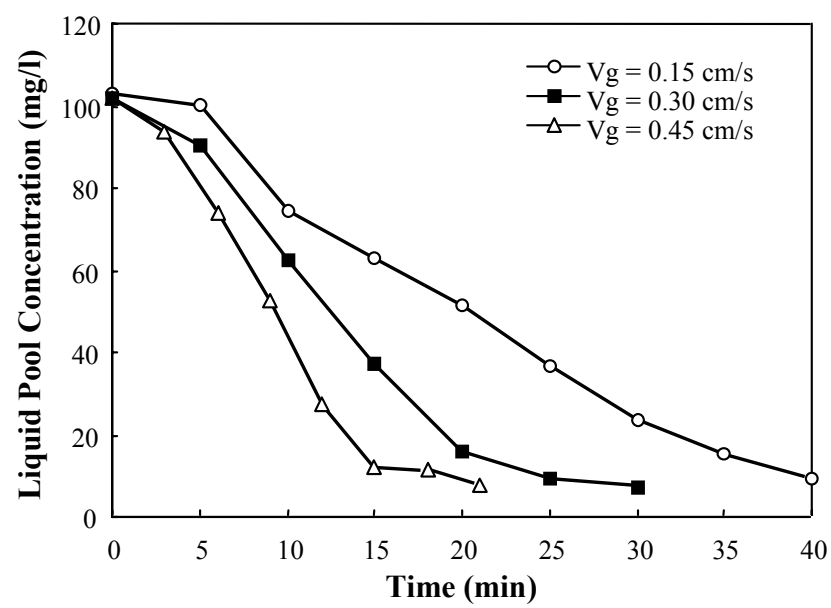

Figure 9: Variation in the liquid pool concentration with time and superficial gas velocity.

\section{Comparison Between the Model and Experimental Data}

To solve the system composed of equations (4) and (8), the value of the volumetric mass transfer coefficient $\left(\mathrm{k}_{\mathrm{L}} \mathrm{a}\right)$ is used. In order to determine the $\mathrm{k}_{\mathrm{L}} \mathrm{a}$ value using the correlation of Özturk et al. (1987), the diffusion coefficient of the protein must be known. Experiments were conducted using a quasi-elastic light-scattering technique to determine the diffusion coefficient of bovine serum albumin in phosphate buffer at $25^{\circ} \mathrm{C}$. The concentration of protein solution used in these experiments was 2500 $\mathrm{mg} / \mathrm{l}$. This was the lowest concentration of protein for which it was possible to obtain data on diffusion coefficient and protein size. The mean value of the diffusion coefficient of BSA obtained from the experiments was $5.89 \times 10^{-7} \mathrm{~cm}^{2} / \mathrm{s}$. This result is in agreement with the diffusion coefficient values presented by Tyn and Gusek (1990), which are in the range of $5.81 \times 10^{-7}$ to $6.15 \times 10^{-7} \mathrm{~cm}^{2} / \mathrm{s}$. The mean effective diameter of the protein was $7.2 \mathrm{~nm}$, which agrees with the value obtained by Yarmush et al. (1988). This diameter means that the protein is not aggregated under the experimental condition used.

In Figures 10, 11, and 12 a comparison between the model for the variation under liquid pool surfactant concentration with time and experimental data for semi-batch foam fractionation of BSA solutions in phosphate buffer for superficial gas velocities of $0.15,0.30$, and $0.45 \mathrm{~cm} / \mathrm{s}$ is shown. As the model takes into account that the concentration 
of surfactant in the drainage stream is almost equal to the concentration of surfactant in the liquid, the second experimental point was used as the first point of simulation. The model was solved using the values of $\mathrm{k}_{\mathrm{L}} \mathrm{a}$ obtained from Özturk et al. (1987), either assuming the correlation considering the bubble diameter to be constant and equal to $3 \mathrm{~mm}$ or using the experimental variation in bubble diameter. The experimental results were between the simulated values applying the two values of $\mathrm{k}_{\mathrm{L}} \mathrm{a}$. The problem with using $\mathrm{k}_{\mathrm{L}} \mathrm{a}$ correlations obtained for bubble columns is that the bubble diameters in these systems

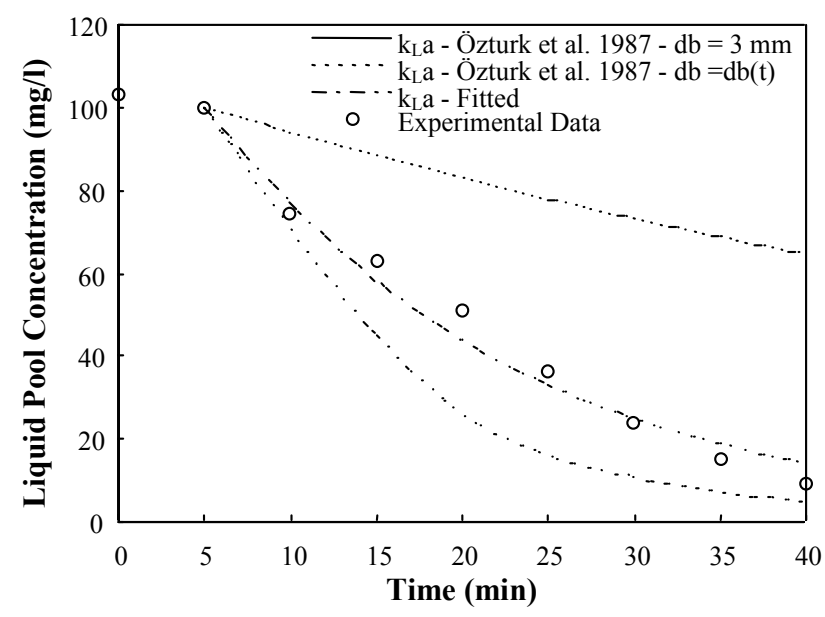

Figure 10: Comparison between experimental data and the model for a superficial gas velocity of $0.15 \mathrm{~cm} / \mathrm{s}$. are generally bigger than in foam fractionation columns due to the presence of surfactants. Thus, the $\mathrm{k}_{\mathrm{L}}$ a value was used as an adjustable parameter in order to fit the experimental data for the foam fractionation of BSA solutions. The values obtained for $\mathrm{k}_{\mathrm{L}}$ a were $9.50 \times 10^{-4}, 1.65 \times 10^{-3}$, and $2.00 \times 10^{-3} \mathrm{~s}^{-1}$ for superficial gas velocities of $0.15,0.30$, and $0.45 \mathrm{~cm} / \mathrm{s}$, respectively. From the adjusted values of $\mathrm{k}_{\mathrm{L}}$ a one can determine the dependence of this value on the superficial gas velocity, given by $\mathrm{k}_{\mathrm{L}} \mathrm{a} \propto \mathrm{V}_{\mathrm{g}}^{0.69}$, which is very similar to the value of 0.68 in the correlation Ozturk et al. (1987).

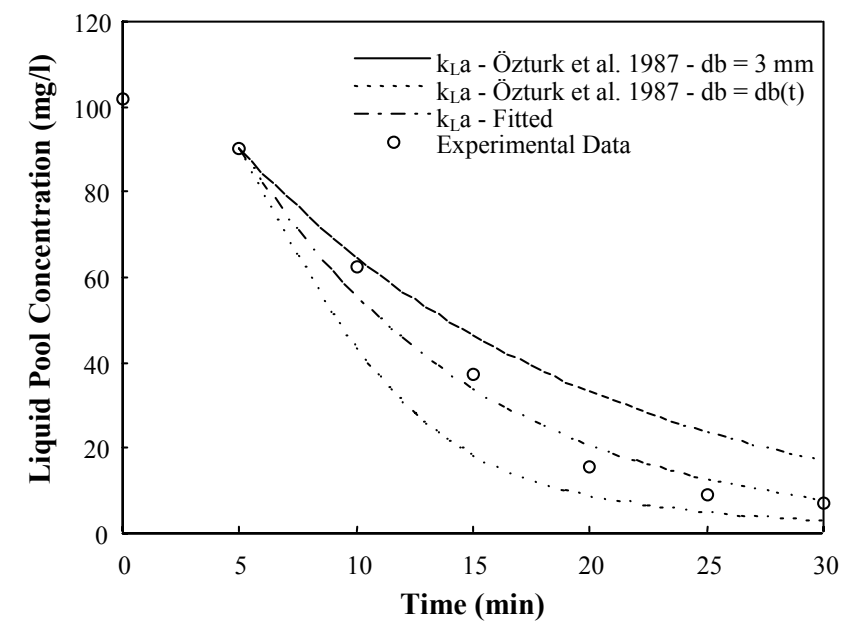

Figure 11: Comparison between experimental data and the model for a superficial gas velocity of $0.30 \mathrm{~cm} / \mathrm{s}$.

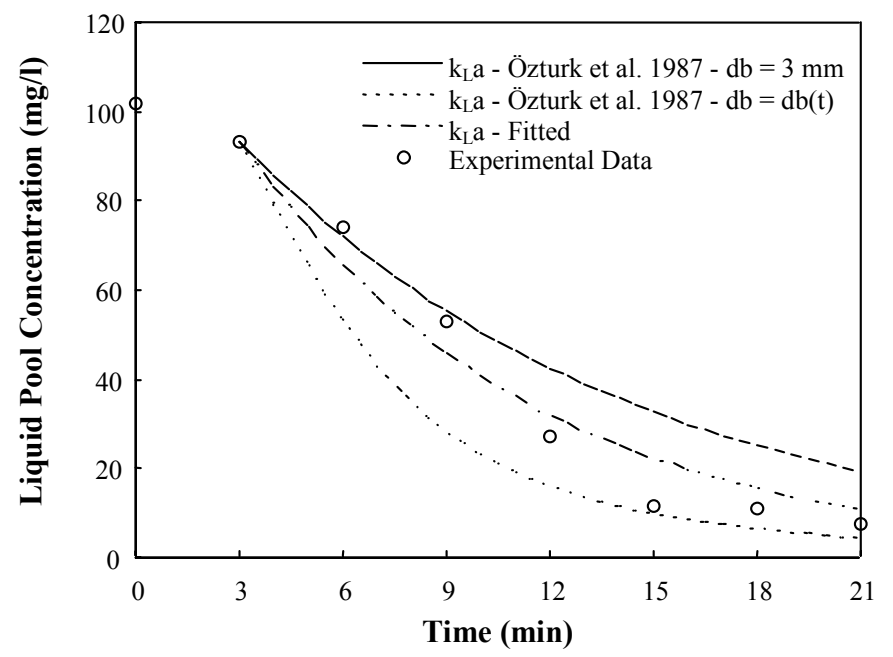

Figure 12: Comparison between experimental data and the model for a superficial gas velocity of $0.45 \mathrm{~cm} / \mathrm{s}$. 
The model was used to predict the experimental variation in liquid pool concentration of cetyltrimethylammonium bromide (CTAB) obtained by Morgan et al. (1992). The adsorption isotherm of this system was presented by Morgan et al. (1992) and can be represented by an Langmuir isotherm. The diffusion coefficient of this surfactant was estimated by Morgan et al. (1992) as $5.6 \times 10^{-6}$ $\mathrm{cm}^{2} / \mathrm{s}$. Figure 12 shows a comparison between the model and the experimental data of Morgan et al. (1992). In this system the foam column is more stable and the simulation started with the first experimental point. One can observe that the model can satisfactorily describe the experimental data and is independent of the $\mathrm{k}_{\mathrm{L}}$ a value. The behavior of the adsorption of CTAB and BSA at the gas-liquid interface can be observed in Figure 14. The value of the concentration of surfactant in the sublayer region $\left(\mathrm{C}_{\mathrm{S}}\right)$ at the exit of the liquid pool is practically equal to the bulk concentration of surfactant for $\mathrm{CTAB}$, while this value is very different for the BSA experiments. This can be explained by the higher diffusion coefficient of the CTAB (almost ten times the BSA diffusion coefficient) and by the fact that CTAB can form only a monolayer of adsorption at the bubble surface, while the protein can form multilayers of adsorption (Graham and Phillips, 1979).

At the beginning of the experiments of semibatch foam fractionation of BSA solutions, the relation between the real surface concentration and the maximum surface concentration $\left(\Gamma\left(\mathrm{C}_{\mathrm{B}}\right)\right)$ decreases with time due to the decrease in liquid pool height and because of the increase in $1 /\left(\mathrm{C}_{b}-\mathrm{C}_{\mathrm{S}}\right)$ due to the decrease in $\mathrm{C}_{\mathrm{b}}$. After a given time, the bubble diameter increases and one can observe in Figure 14 that the relative surface concentration increases. The decrease in the percentage of maximum surface concentration occurs due to the continuous increase in $1 /\left(\mathrm{C}_{\mathrm{b}}-\mathrm{C}_{\mathrm{S}}\right)$.

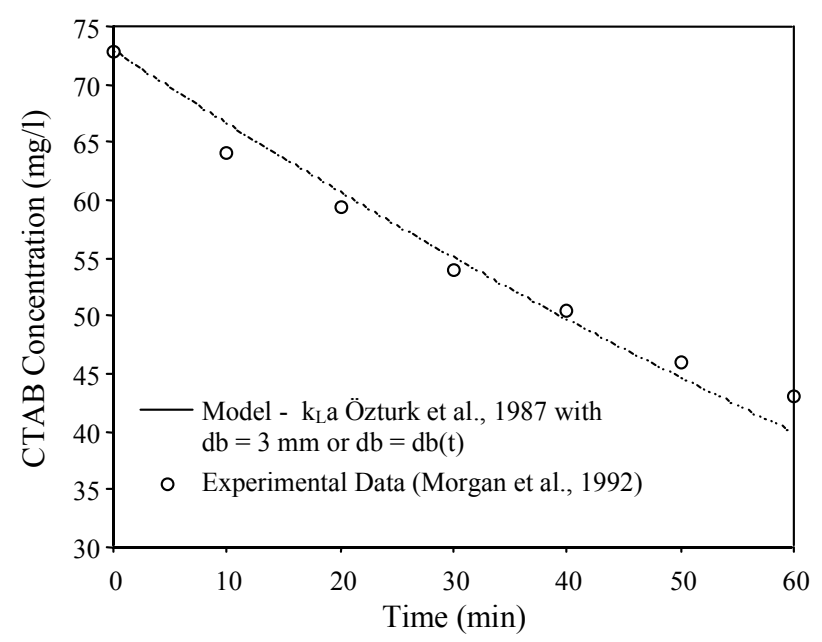

Figure 13: Results for semi-batch foam fractionation of a solution with an initial protein concentration of $316.9 \mathrm{mg} / 1$ and a superficial gas velocity of $0.30 \mathrm{~cm} / \mathrm{s}$.

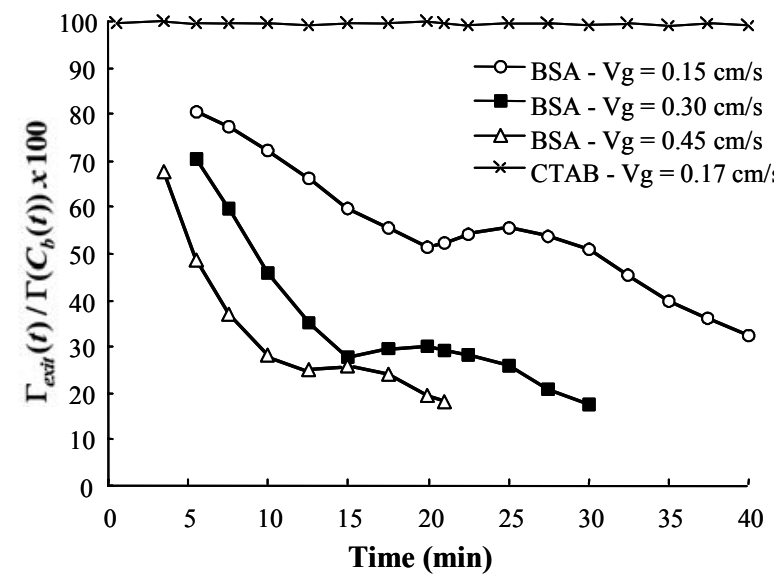

Figure 14: Behavior of the surfactant adsorption at the gas-liquid interface as a function of time.

The abscissa is the ratio between the real surface concentration at the exit of the liquid pool and the surface concentration calculated in equilibrium with the bulk concentration. 


\section{CONCLUSIONS}

Foam fractionation was shown to be a useful method either to concentrate diluted solutions of BSA or to decrease the amount of surfactant in a solution. It was observed that the method was more effective for low initial protein concentrations and low superficial gas velocities. Under the experimental conditions used in this work, it was possible to obtain solutions at the top of the fractionation column with concentrations between two and five time higher than the initial one and the final concentration of protein in the liquid pool was around ten times lower than the initial concentration.

The photographic method used allowed determination of the distribution of bubble size in the liquid pool. The Sauter bubble diameter increased with the increase in superficial gas velocity and with time.

The experimental data for variation in BSA and CTAB concentrations with time could be satisfactorily represented by the model developed.

\section{ACKNOWLEDGMENT}

One of the authors, P.T.V.R., would like to acknowledge the scholarship provided by Conselho Nacional de Pesquisa e Desenvolvimento Científico, CNPq.

$\begin{array}{llr}\mathrm{H} & \text { Liquid pool height, } \\ \mathrm{k}_{\mathrm{L}} & \text { Volumetric mass transfer } \\ & \text { coefficient, } \\ \mathrm{n}_{\mathrm{i}} & \text { Number of bubbles per class } \\ \mathrm{Q} & \text { Gas flow rate, } \\ \mathrm{t} & \text { Time, } \\ \mathrm{V} & \text { Ascension velocity of the } & (-) \\ & \text { bubbles, } & \mathrm{L} / \mathrm{T} \\ \mathrm{V} & \text { Volume of the liquid pool, } \\ \mathrm{V} b & \text { Volume of one bubble in the } \\ & \text { liquid pool, } \\ \mathrm{V}_{\mathrm{g}} & \text { Superficial gas velocity, } \\ \mathrm{z} & \text { Axial position in the liquid pool, } & \mathrm{L}^{3} \\ & \end{array}$

\section{Greek Symbols}

Eg Gas fraction in the liquid pool

$\gamma \quad$ Surface tension, $\quad \mathrm{M} / \mathrm{T}^{2}$

$\Gamma \quad$ Surface concentration, $\quad \mathrm{M} / \mathrm{L}^{2}$

$\Gamma$ exit Surface concentration at the exit $\quad \mathrm{M} / \mathrm{L}^{2}$

$\Gamma_{\mathrm{m}} \quad$ of the liquid pool, concentration in the liquid pool,

$\mu 1 \quad$ Liquid viscosity, $\quad$ M/LT

$\rho_{1} \quad$ Liquid density, $\quad \mathrm{M} / \mathrm{L}^{3}$

$\rho_{\mathrm{g}} \quad$ Gas density, $\quad \mathrm{M} / \mathrm{L}^{3}$

$\tau \quad$ Time (of the ascension of one $\quad \mathrm{T}$ bubble),

\section{NOMENCLATURE}

$\mathrm{A}_{\mathrm{b}} \quad$ Area of one bubble in the liquid pool,

$\mathrm{A}_{\mathrm{c}} \quad$ Area of the sublayer,

$\mathrm{Cb}_{\mathrm{b}} \quad$ Surfactant concentration in the liquid pool,

$\mathrm{C}_{\mathrm{bo}} \quad$ Initial surfactant concentration in the liquid pool,

$\mathrm{C}_{\mathrm{d}} \quad$ Surfactant concentration in the drainage stream,

$\mathrm{C}_{\mathrm{f}} \quad$ Surfactant concentration in the upstream,

$\mathrm{C}_{\mathrm{S}} \quad$ Surfactant concentration in the $\quad \mathrm{M} / \mathrm{L}^{3}$ sublayer,

$\mathrm{d}_{\mathrm{b}} \quad$ Bubble diameter,

D Drainage flow rate at the exit of $\quad \mathrm{L}^{3} / \mathrm{T}$ the liquid pool,

$\mathrm{D}_{\mathrm{i}} \quad$ Diffusion coefficient,

F Up flow rate at the exit of the liquid pool,

g gravity acceleration
$\mathrm{L}^{2}$

$\mathrm{M} / \mathrm{L}^{3}$

$\mathrm{M} / \mathrm{L}^{3}$

$\mathrm{M} / \mathrm{L}^{3}$

$\mathrm{L}$

$1 / \mathrm{T}$

$\mathrm{L}^{3} / \mathrm{T}$

$\mathrm{L} / \mathrm{T}^{2}$

\section{REFERENCES}

Ahmad, S. I., Laws of Foam Formation and Foam Fractionation, Separation Science, 10, 673-688 (1975).

Ahmed, M. and Dickinson, E., Effect of Ethanol on the Foaming of Aqueous Protein Solutions, Colloids and Surfaces, 47, 353-365 (1990).

Akita, K. and Yoshida, F., Gas Holdup and Volumetric Mass Transfer Coefficient in Bubble Columns, Industrial Engineering Chemistry Process Design and.Development,12, 76-80 (1973).

Akita, K., Effect of the Electrolyte on the Mass Transfer Characteristics of a Bubble Column, International Chemical Engineering, 29, No. 1, 127135 (1989).

Bradford, M.M., A Rapid and Sensitive Method for the Quantitation of Microgram Quantities of Protein Utilizing the Principle of Protein-Dye Binding ,Analytical Biochemistry, 72, 248-254 (1976). 
Brown, L.; Narsimhan, G., and Wankat, P.C., Foam Fractionation of Globular Proteins, Biotechnology and Bioengineering, vol. 36, 947-959 (1990).

Cho, J.S. and Wakao, N., Determination of LiquidSide and Gas-Side Volumetric Mass Transfer Coefficients in a Bubble Column, Journal of Chemical Engineering of Japan, 21, No. 6, 576581 (1988).

Deckwer, W.D. and Schumpe, A., Improved Tools for Bubble Column Reactor Design and ScaleUp, Chemical Engineering Science, 48, No. 5, 889-911 (1993).

Du, L., Ding, Y., Prokop, A. and Tanner, R.D., Measurement of Bubble Size Distribution in Protein Foam Fractionation Column using Capillary probes with Photoelectric Sensors, Applied Biochemistry and Biotechnology-Part A, 91-93, 387-404 (2001).

Fainerman, V.B., Lucassen-Reynders, E.H., and Miller, R., Description of the Adsorption Behaviour of Proteins at Water/Fluid Interfaces in the Framework of a Two-Dimensional Solution Model, Advances in Colloids and Interface Science, 106, 237-259 (2003).

Gehle, R.D. and Schügerl, K., Protein Recovery by Continuous Flotation, Applied Microbiology and Biotechnology, 20, 133-138 (1984).

Graham, D.E. and Phillips, M.C., Proteins at Liquid Interfaces II. Adsorption Isotherms, Journal of Colloids and Interface Science, 70, No.3, 415-426 (1979).

Guzman, R.Z., Carbonell, R.G., and Kilpatrick, P.K., The Adsorption of Proteins to Gas-Liquid Interfaces, Journal of Colloid and Interface Science, 114, 536 - 549 (1986).

Hikita, H., Asai, S., Tonigawa, K., Segawa, K., and Kitao, M., The Volumetric Liquid-Phase Mass Transfer Coefficient in Bubble Columns, Chemical Engineering Journal, 22, 61-67 (1981).

Kawase, Y., Halard, B., and Moo-Young, M., Theoretical Predictions of Volumetric Mass Transfer Coefficients in Bubble Columns for Newtonian and Non-Newtonian Fluids, Chemical Engineering Science,„42, 1609-1617 (1987).
Lalchev, Z. and Exerowa, D., Concentration of Proteins by Foaming, Biotechnology and Bioengineering, Vol. XXIII, 669-676 (1981).

Manev, E. D., Sazdanova, S.V., and Wasan, D.T., Emulsion and Foam Stability, The Effect of Film Size on Film Drainage, Journal of Colloid and Interface Science, 97, No. 2, 591-594 (1984).

Morgan, J. D., Napper, D. H., Warr, G.G., and Nicol, S.K., Kinetics of Recovery of Hexadecyltrimetylammonium Bromide by Flotation, Langmuir, 8, 2124-2129 (1992).

Noel, J., Prokop, A., and Tanner, R.D., Foam Fractionation of a Dilute Solution of Bovine Lactoferrin, Applied Biochemistry and Biotechnology, 98-100, 395-402 (2002).

Özturk, S. S., Schumpe, A., and Deckwer, W.D., Organic Liquids in a Bubble Column: Holdups and Mass Transfer Coefficients, AIChE Journal, 33, No. 9, 1473-1480 (1987).

Rand, P.B. and Kraynik, A.M., Drainage of Aqueous Foams: Generation, Pressure and Cell-Size Effects, Society of Petroleum Engineers Journal, 152-154 (1983).

Santana, C.C., Du, L., and Tanner, R.D., Downstream Processing of Proteins Using Foam Fractionation, In: Encyclopedia of Life Support Systems, EOLSS Publishers Co. Ltd., 6, 1-18 (2003).

Sarma, D.S.H.S.R. and Khilar, K.C., Effects of Initial Gas Volume Fraction on Stability of Aqueous Air Foams, Industrial and Engineering Chemistry Research, 27, No. 5, 892-894 (1988).

Tyn, M.T. and Gusek, T.W., Prediction of Diffusion Coefficients of Proteins, Biotechnology and Bioengineering, 35, No. 4, 327-338 (1990).

Ward, A. F. H. and Tordai, L., Time- dependence of Boundary Tensions of Solutions: I. The Role of Diffusion in Time-Effects, The Journal of Chemical Physics, 14, No. 7, 453-461 (1946).

Yarmush, D. M., Murphy, R.M., Colton, C. K., Fisch, M. and Yarmush, M.L., Quasi-Elastic Light Scattering of Antigen-Antibody Complexes, Molecular Immunology, 25, No. 1, 17-32 (1988). 